\title{
Understand Daily Fire Suppression Resource Ordering and Assignment Patterns by Unsupervised Learning
}

\author{
Yu Wei ${ }^{1, *(1)}$, Matthew P. Thompson ${ }^{2}$, Erin J. Belval ${ }^{1}$, David E. Calkin ${ }^{3}$ and Jude Bayham ${ }^{1}$ \\ 1 Department of Forest and Rangeland Stewardship, Colorado State University, Fort Collins, CO 80523, USA; \\ erin.belval@colostate.edu (E.J.B.); jude.bayham@colostate.edu (J.B.) \\ 2 Rocky Mountain Research Station, USDA Forest Service, Fort Collins, CO 80526, USA; \\ matthew.p.thompson@usda.gov \\ 3 Rocky Mountain Research Station, USDA Forest Service, Missoula, MT 59801, USA; dave.e.calkin@usda.gov \\ * Correspondence: yu.wei@colostate.edu
}

check for updates

Citation: Wei, Y.; Thompson, M.P.; Belval, E.J.; Calkin, D.E.; Bayham, J. Understand Daily Fire Suppression Resource Ordering and Assignment Patterns by Unsupervised Learning. Mach. Learn. Knowl. Extr. 2021, 3, 14-33. https://dx.doi.org/10.3390/ make3010002

Received: 14 November 2020 Accepted: 18 December 2020 Published: 23 December 2020

Publisher's Note: MDPI stays neutral with regard to jurisdictional claims in published maps and institutional affiliations.

Copyright: () 2020 by the authors. Licensee MDPI, Basel, Switzerland. This article is an open access article distributed under the terms and conditions of the Creative Commons Attribution (CC BY) license (https: / / creativecommons.org/ licenses/by/4.0/).

\begin{abstract}
Wildland fire management agencies are responsible for assigning suppression resources to control fire spread and mitigate fire risks. This study implements a principle component analysis and an association rule analysis to study wildland fire response resource requests from 2016 to 2018 in the western US to identify daily resource ordering and assignment patterns for large fire incidents. Unsupervised learning can identify patterns in the assignment of individual resources or pairs of resources. Three national Geographic Area Coordination Centers (GACCs) are studied, including California (CA), Rocky Mountain (RMC), and Southwest (SWC) at both high and low suppression preparedness levels (PLs). Substantial differences are found in resource ordering and assignment between GACCs. For example, in comparison with RMC and SWC, CA generally orders and dispatches more resources to a fire per day; CA also likely orders and assigns multiple resource types in combination. Resources are more likely assigned to a fire at higher PLs in all GACCs. This study also suggests several future research directions including studying the causal relations behind different resource ordering and assignment patterns in different regions.
\end{abstract}

Keywords: wildland fire; suppression; principle component analysis; association rule analysis

\section{Introduction}

The assignment of wildland fire suppression resources is one of the primary tasks of the fire management agencies responsible for controlling fire spread and mitigating fire risks [1]. Our current understanding of suppression resource use during fire events may still be limited, including how resources interact together and whether they can work synergistically [2]. Some past studies show that both ground and aerial resources may be assigned to a fire to accomplish multiple tasks such as fireline production, mop-up, preparation for burnout operations, or point protection [3]. Suppression resource ordering and assignments follow certain patterns and identifying those patterns could help improve our understanding of suppression resource demands, collaborations, and effectiveness. For example, ref. $[4,5]$ suggest that suppression resources allocation, assignment, and interaction could be influenced by factors such as values to be protected, fire growth potential, and landscape conditions. Managers often use weather forecasts to predict fire growth and order resources accordingly [6]. In a study of aerial resource uses, ref. [7] suggested that large airtankers generally follow guidelines for operational speed and altitude, but their uses are not always effective with respect to fire response phase, terrain, fuels, and time of day. Meanwhile, ref. [8] demonstrated that suppression resource use may vary between incident management teams, e.g., 17 out of the 89 teams in the US exhibit significantly higher resources demands than the median level of all teams. Those discoveries provide the base for us to continuously study fire suppression resource ordering and assignment in the US, and potentially in other regions of the world as well. 
Many machine-learning models have been implemented to study wildfire risks and managements. A complete review of those efforts is provided by [9]. Here are a few examples. Ref. [10] compared the performances of an artificial neural network model (ANN) and a support vector machine (SVM) model to predict fire occurrence in Canada based on the normalized difference vegetation index, the land surface temperature, and the thermal anomalies. Ref. [11] compared a LogitBoost ensemble decision tree method with SVM, random forest (RF), and Kernel logistic regression models to predict forest fire susceptibility in Vietnam. Ref. [12] developed an RF model to estimate the probability of containing fire in different locations of a landscape based on topography, distance to natural and anthropogenic barriers to fire spread, suppression difficulties at those locations, and the travel costs for suppression resources to reach those locations. Ref. [13] developed an ANN model to estimate wildfire probability as a function of biophysical and humanrelated drivers in Italy. Those studies demonstrate the potential of using machine learning models to study wildfire problems.

The US National Interagency Fire Center (NIFC) divides the US into regions known as Geographic Area Coordination Centers (GACC) to support fire suppression decisionmaking and regional forecasting. The western contiguous USA includes seven GACCs: Southern California, Northern California, Northwest, Northern Rockies, Rocky Mountains, Great Basin, and Southwest. Due to the differences in climate, topography, and social economic conditions, ref. [14] suggested there are many differences in fire complexity dynamics between those regions. Fire suppression resource utilization also varies between GACCs. Ref. [15] suggest the capacity of contracted fire suppression equipment varies across the western US and is concentrated more in the northwest and northern California. Ref. [16] found significant variation of suppression resource demands between the central/southern Rockies and California.

The US National Wildfire Coordinating Group (NWCG) fire suppression tactical guide (referred to as the "suppression guide" in this study) [17] summarizes GACC-specific fire suppression tactics and resource use considerations, including certain similarities and distinctions between GACCs. The NWCG suppression guide are informative, but it is difficult to compare regions based only on qualitative descriptions. In this study, we implement unsupervised learning models including principle component analysis (PCA) and association rule analysis (ARA) to mine the historical daily fire suppression resources ordering and assignment data to quantitatively compare the suppression resource use patterns between selected GACCs. For simplicity, our study combines the two GACCs of California into one common GACC referred to as ' $\mathrm{CA}$ ' because both the northern California and southern California GACCs share common governance structures for wildland fire suppression. CA is selected due to its long history of large and damaging fires. We also include the Rocky Mountain GACC (RMC) and the Southwest GACC (SWC) into analyses. According to [17], all three GACCs have diversified topography, fuel types, and weather conditions that support different fire behaviors. SWC may have the least favorable road access conditions comparing with the other two GACCs, while CA may have the best road system to support equipment and crew transportation. CA may also have the highest levels of engine, hand crew, dozer, and aircraft availability. Our analysis also compares resource use under different preparedness levels (PLs) [18].

Discoveries from our study could help fire managers and policymakers better understand the suppression resource ordering, assignment, and collaborations for different regions. Results may help national or regional resource dispatching authorities to predict demands for suppression resources and inform agency and interagency resource acquisition and allocation strategies. Discoveries through the unsupervised learning methods also help us identify and prioritize future research directions to explore regional suppression resource needs and potential limitations as well as improve the efficiency of resource allocation and collaboration. 


\section{Materials and Methods}

\subsection{Resource Ordering and Status System (ROSS)}

The Resource Ordering and Status System (ROSS) is a database used in the US to track suppression resource requests, dispatching, and release for large fire incidents during each fire day [19]. ROSS has been broadly adopted for tracking interregional resource movements for large fire suppression since 2012 [1,20]. ROSS has also been used to study seasonal fire suppression requests [6], suppression resource productivity and effectiveness [8], and resource dispatching and transferring between fire management regions [21]. In this study, we extract filled suppression resource request, mobilization, and demobilization data from archived ROSS data for requests occurring between 1 January 2016 and 31 December 2018. Two types of data were created from ROSS: daily resource ordering data and daily resource assignment data for every incident. The number of resources assigned to a fire each day reflects the cumulative effect of daily resource ordering and demobilization (e.g., hand crews may be assigned to a fire for up to 14 days). Some resource requests through ROSS may not be filled due to resource scarcity or changing fire situations. Unfilled requests were not included in our analysis. Our final data tables include 192,264 daily filled resource orders and 459,633 daily assignment records from ROSS in the three GACCs from 2016 to 2018. There are more assignment records than order records because each filled order may result in resource assignments that last multiple days; one exception is airtankers, which are typically reassigned daily.

The ROSS database does not store fire incident information such as fire sizes or fire durations. We can estimate the duration of each fire by calculating the number of days between the earliest and the latest assignments of all resources to that fire. Fire duration frequencies show that there are more fires with shorter durations in all tested GACCs. We find CA has more fires in almost all fire duration bins than the other two GACCs (Figure 1). Although fire duration distributions between RMC and SWC are similar, [17] suggests there are substantial differences between them regarding landscape topography, fuel types, value to protect, fire weather, etc. Figures A1 and A2 in Appendix A also show very different daily resource ordering and assignment patterns between RMC and SWC.

\subsection{Preparedness Levels}

Fire managers in the US often use preparedness levels (PL) to assist with resource assignment decisions. PL is a scaled numeric value between 1 and 5 [18] that reflects the current and projected levels of resource commitment and whether resource placement is enough to meet anticipated needs. A PL of 1 indicates low fire activity and high resource availability, whereas a PL of 5 indicates high fire activity and low resource availability. National PL is determined by the NMAC. According to the rules for national PL classification, PL 1 or 2 reflects no or minimal interregional resource movements, while PL 3, 4 , and 5 reflect substantial interregional resource movements between regions to meet resource demands. Each GACC also establishes its own PL following similar principles. For example, in CA, the GACC PL will be set at 3 when the probability of a class D fire (between 100 to 300 acres) increases; in case CA cannot fill many outstanding resource requests and needs to request resources from NICC, a PL of 5 is often justified [22]. In this study, we use GACC-specific PL to describe regional fire activity and resource availability. To simplify the analysis, we further group GACC's daily PLs into two categories: lower PLs (1 and 2$)$ and higher PLs (3, 4, and 5). ROSS records are synchronized with GACC PLs based on the common dates and fire occurrence locations to compare daily filled suppression resource ordering and assignment for each fire incident.

\subsection{Suppression Resource Categories and Collaborations}

We adopt two suppression resources categorization schemes (Table 1) to provide analyses with different levels of details: (1) suppression resources are classified into seven general categories; and (2) suppression resources are further classified into more detailed 23 subcategories. Tests using different schemes allow us to study resource collaborations at 
different scales. For example, although fire engines belong to a general resource category commonly seen in all GACCs, the more specific "engine teams" represent a subcategory of engine resources that has mostly been used in California.

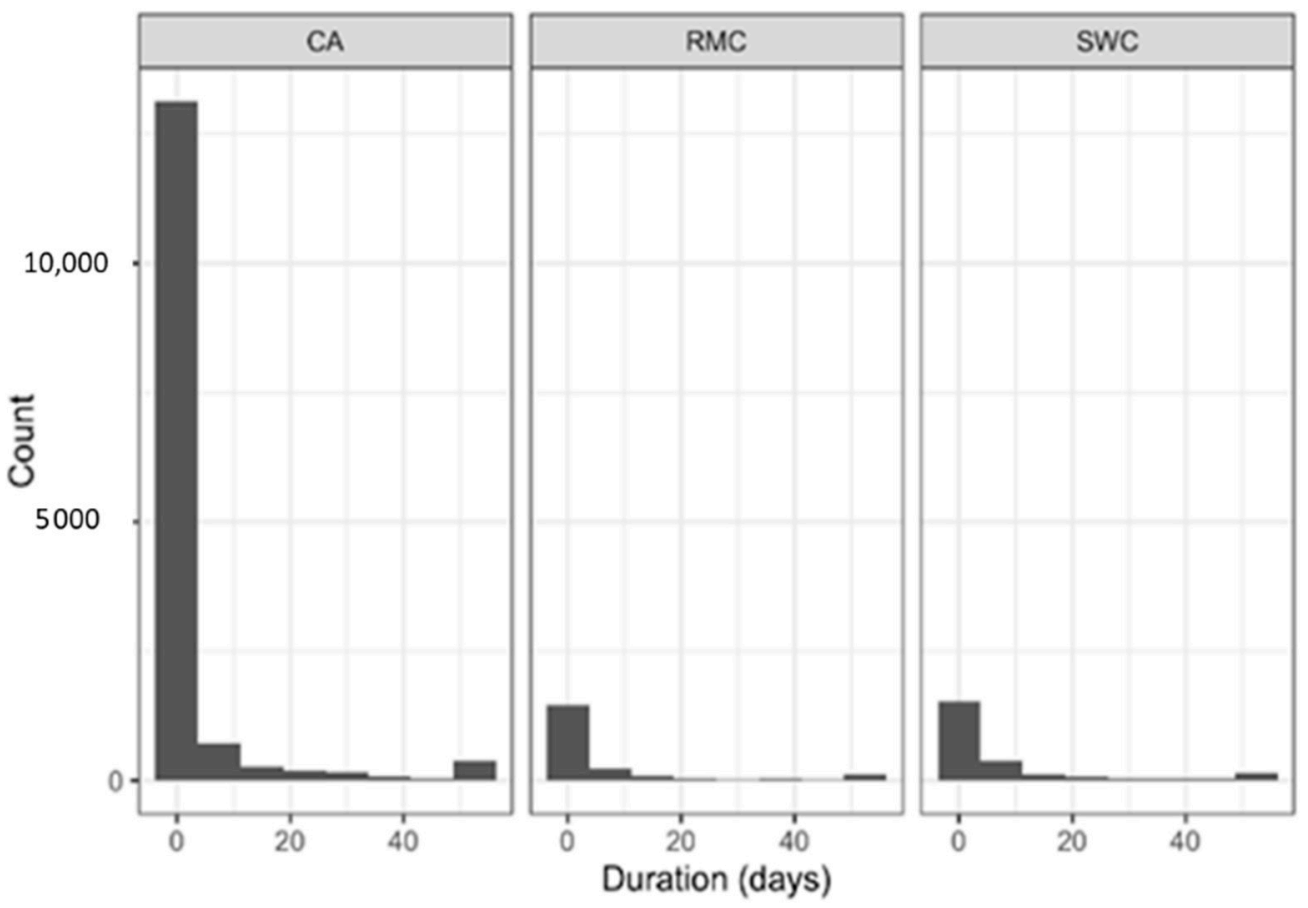

Figure 1. The total number of fires of different durations in the three Geographic Area Coordination Centers (GACCs) during the three-year analysis period from 2016 to 2018.

Different resources may play different roles at different stages of fire suppression [23]. For example, crews are often assigned to build firelines, conduct mop up, develop contingency lines, and prepare for burnout and point protection [8]. Crews, dozers, engines, helicopters, and airtankers not only directly produce fireline but also contribute to many other suppression objectives. Resources may have complementary functions or substitute each other under certain circumstances. For example, dozers, crews and engines often work together for the production of direct or indirect firelines or point protection [24]. Helicopters and airtankers both drop chemicals or water to slow or halt fire progression, or to knock down spotting fires, usually in support of efforts by ground resources [25,26]; they can also be used for transportation or surveillance [8]. Helicopters and fixed-wing airplanes can be used to carry crews to desired locations. A lead plane is typically ordered together with an airtanker to provide support [27]. There are also restrictions on the use of certain resources under different circumstances. For example, structure engines often require better road conditions than wildland engines. Aerial operations are feasible, safe, and effective only under specific weather conditions and for certain fuel types. Additional descriptions about different suppression resource categories can be found in [8].

Figure 2 displays the total number of days on assignment from each studied resource type from 2016 to 2018 in the three studied GACCs at both high and low PLs. "Days on assignment" roughly reflects the total workload from each resource type during the threeyear period. Graphs show that engines by far have been the most widely used resource types during fire suppression, which is followed by crews and helicopters in most cases. Additional figures are presented in Appendix A. 
Table 1. Suppression resource categories and subcategories used in the study.

\begin{tabular}{|c|c|c|}
\hline Categories & Subcategories & Descriptions \\
\hline Airtanker & $\begin{array}{l}\text { Small airtanker, } \\
\text { large airtanker }\end{array}$ & $\begin{array}{l}\text { - Fixed-wing aircraft certified by FAA as being capable of transport } \\
\text { and delivery of retardant solutions. }{ }^{1}\end{array}$ \\
\hline Crew & $\begin{array}{l}\text { Military crew, crew team, } \\
\text { type 1, initial attack, type } 2\end{array}$ & $\begin{array}{l}\text { - Groups of approximately } 20 \text { firefighters trained and organized. } \\
\text { Type } 1 \text { crew has the highest level of training; type } 2 \text { with IA } \\
\text { (initial attack) capability is referred as initial attack crew. }{ }^{5}\end{array}$ \\
\hline Dozer & Dozer team, dozer & $\begin{array}{l}\text { Tracked vehicle with a front mounted blade used for exposing } \\
\text { mineral soil. } \\
\text { - A dozer team includes multiple dozers lead by a team boss. }{ }^{6}\end{array}$ \\
\hline Engine & $\begin{array}{l}\text { Engine team, structure } \\
\text { engine, wildland engine }\end{array}$ & $\begin{array}{l}\text { - Ground vehicle providing specified levels of pumping, water, } \\
\text { and hose capacity. } \\
\text { - Structure engine are larger with more tank capacity, higher } \\
\text { pumping rate, and longer hose; wildland engines are smaller. } \\
\text { - Engine team is a team of five engines with between } 11 \text { and } 21 \\
\text { total personnel. }\end{array}$ \\
\hline Water Tender & Water tender & $\begin{array}{l}\text { - Ground vehicle capable of transporting specified quantities of } \\
\text { water. }\end{array}$ \\
\hline Helicopter & Type 1 , type 2 , type 3 & $\begin{array}{l}\text { - A rotary-wing aircraft that can be fitted with a tank or carry a } \\
\text { bucket with water or fire retardant. } \\
\text { - Type } 1 \text { helicopter is the largest; type } 3 \text { is the smallest. }\end{array}$ \\
\hline Fixed wing & $\begin{array}{l}\text { Lead plane, tactical, cargo, } \\
\text { infrared, passenger, recon, } \\
\text { smokejumper }\end{array}$ & $\begin{array}{l}\text { Lead plane makes trial runs over the target area to check wind, } \\
\text { smoke conditions, topography and to lead air tankers to targets } \\
\text { and supervise their drops. The use of a lead plane increases the } \\
\text { effectiveness, economy, and safety of air tanker operations. } \\
\text { Tactical aircraft flies over an incident, providing tactical } \\
\text { coordination with the incident commander on the ground, } \\
\text { and directing airtankers and helicopters to critical areas of a fire } \\
\text { for retardant and water drops. }\end{array}$ \\
\hline
\end{tabular}

${ }^{1}$ https://www.nwcg.gov/term/glossary/airtanker. ${ }^{2}$ https://www.fs.fed.us/r6/fire/pnwcg/aviation/2008/08MasterAPM-Edition.pdf. ${ }^{3}$ https://gacc.nifc.gov/swcc/dc/azpdc/operations/documents/aircraft/links/Aircraft\%20Recognition\%20Guide.pdf. ${ }^{4}$ https: / /www.fs. fed.us/t-d/pubs/pdf/00511203.pdf. ${ }^{5}$ https:/ / www.nifc.gov/nicc/mobguide/Chapter\%2030.pdf. ${ }^{6}$ https:/ /ycfd5.org/dozer-team/.

\subsection{PCA Methods}

PCA is a descriptive tool used for reducing the dimensionality of high dimensional datasets, increasing interpretability, but at the same time minimizing information loss [28]. It does so by creating new uncorrelated variables to best capture the variances from the original high-dimensional data. We use PCA to describe and visualize the daily resource ordering and assignment patterns for individual fire incidents in the three GACCs under high and low PLs. We normalize the data so the indicator for the number of resources ordered or assigned daily to each fire would have a value between 0 and 1 . We conduct PCA and use the first two principle components to represent the seven dimensional data corresponding to the seven general resource types in Table 1 . The first principle component PC 1 represents a linear combination of the daily number of orders (or assignments) of each of the seven suppression resource types on each fire. PC 1 is calculated to maximize the percent of variance explained through the selected linear combination. The second 
principle component PC 2 is constructed to capture the maximum amount of remaining variation in the data that is not captured by PC 1.

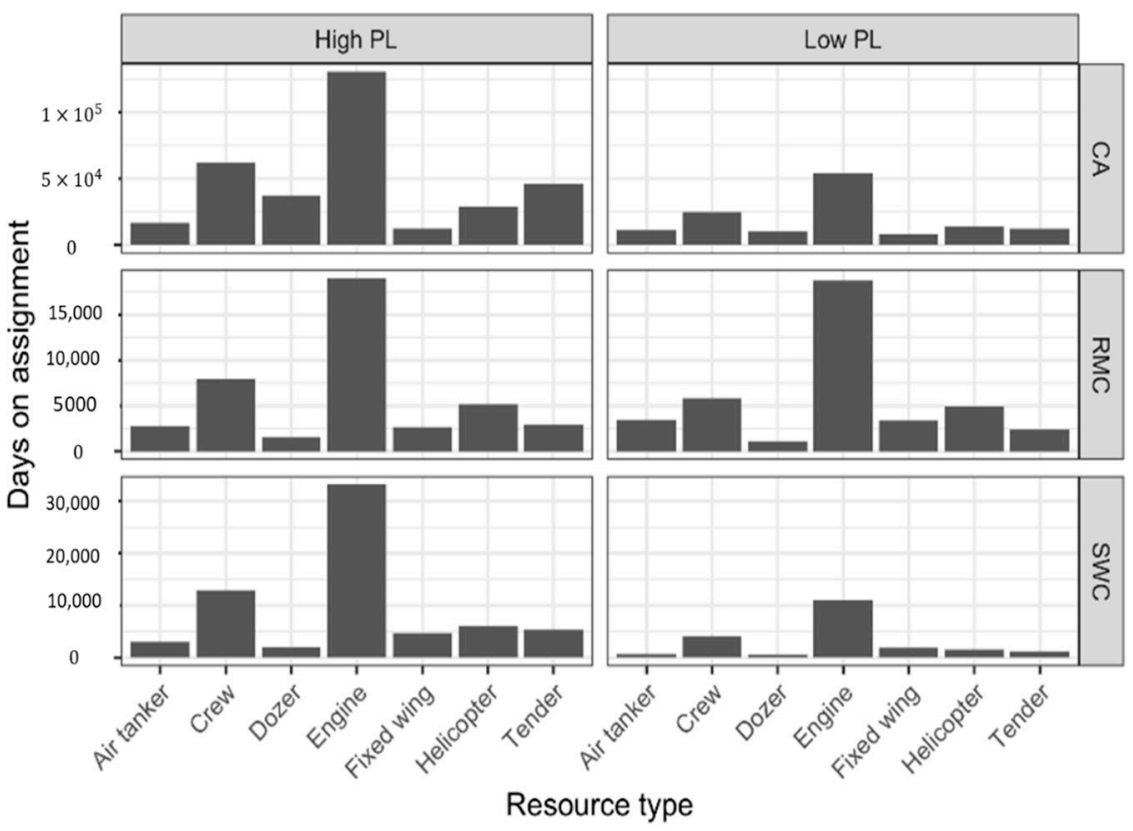

Figure 2. The total number of days each resource type were assigned to fire suppression during the three-year analysis period (2016 to 2018) at high or low preparedness levels (PL).

\subsection{ARA for Resource Categories or Subcategories}

ARA is a frequency-based data mining method and was originally developed to study customer transactions to identify the associations between different purchased items within the same transaction [29]; e.g., eggs and milk are often purchased together by a customer from a grocery store transaction. From a set of transaction $T$, an association rule $r$ is defined as an implication of the form $X \Longrightarrow Y$, where $X$ and $Y$ are subsets of items from all transactions. The sets of items included in subsets $X$ or $Y$ are called antecedent or consequent sets of the rule $r$.

ARA methods have been implemented in some wildland fire studies. For example, [30] use ARA to identify hotspots of lightning and wildfires occurrence in Alberta, Canada. Ref. [31] developed an incremental ARA method to study the correlation between several environmental factors and fire spread. Ref. [32] implemented the Apriori ARA and a fuzzy clustering method to study how wildfire risk may be influenced by variables such as distance to settlement and roads, population density, and landscape conditions in Iran. In this study, we implement the Apriori mining algorithm provided through Python 3.6 to extract the associations between different categories of subcategories of resources ordered or assigned to each fire during each day. To make the results easier to understand, we only study rules $X \Longrightarrow Y$ with one resource category (or subcategory) in either the antecedent set $X$ or the consequent set $Y$. Although it is not difficult to extract rules with multiple resource categories (or subcategories) in either of the sets, complex rules can be difficult to interpret.

We report both the "support" and "confidence" measurements of each identified rule. The support of a rule $X \Longrightarrow Y$ is calculated as the number of transactions with both $X$ and $Y$ in it divided by the total number of studied transactions in $T$. Under the fire suppression context, support measures the probability that resource $X$ and $Y$ were ordered or assigned together.

$$
\text { Support }(\mathrm{X} \Longrightarrow \mathrm{Y})=\operatorname{Support}(\mathrm{Y} \Longrightarrow \mathrm{X})=\frac{\# \text { of times both } X \text { and } Y \text { in transactions }}{\text { the total } \# \text { of studied transactions }}
$$


When we discuss the support of an antecedent set $X$, the number of transactions with $X$ will be divided by the total number of transactions in $T$.

$$
\text { Support of the antedent of rule }(\mathrm{X} \Longrightarrow \mathrm{Y})=\frac{\text { \# of times } X \text { shown up }}{\text { the total \# of studied transactions }}
$$

The confidence of a rule $X \Longrightarrow Y$ is calculated as the number of transactions with both $X$ and $\mathrm{Y}$ in it divided by the total number of transactions with item $\mathrm{X}$ in them.

$$
\text { Confidence }(X \Longrightarrow Y)=\frac{\# \text { of times both } X \text { and } Y \text { in transactions }}{\# \text { of times } X \text { in transactions }}
$$

A higher confidence of rule $X \Longrightarrow Y$ in resource ordering or assignment means that if resources in set $X$ were ordered/assigned to a fire, resources in set $Y$ would more likely be ordered/assigned to the same fire on the same day along with the resources in set $X$. If the confidence of rule $\mathrm{X} \Longrightarrow \mathrm{Y}$ is lower, we may assume that the resource in $\mathrm{X}$ was more likely ordered/assigned to a fire during a fire day without the ordering/assignment of resource in $Y$. Although the support of $X \Longrightarrow Y$ is always the same as the support of rule $Y \Longrightarrow X$ (symmetric), the confidence of $X \Longrightarrow Y$ is usually different from rule $Y \Longrightarrow X$ (asymmetric).

\section{Results}

\subsection{PCA for General Resoruce Ordering and Assignment}

PCA allows us to reduce the dimension of ROSS data to visualize the suppression resource orders and assignments. Our testing shows that PC 1 can explain $61.3 \%$ of the total variance of the original ROSS data; PC 2 explains an additional $22.1 \%$ of the total variance; and PC 3 explains an additional $7.4 \%$ of the total variance. Adding more components into PCA would explain more of the variance, but visualizing data in a high-dimensional space is usually challenging. Figure 3 shows four 2D scatter plots based on the PC 1 and PC 2 calculated from the daily resource ordering and assignment data. Both the resource ordering and resource assignment scatter plots show that more points stretch toward the right end of the $x$-axis (denoting PC 1 ) at the higher PLs. Since PC 1 explains $61.3 \%$ of the variance, this pattern reveals that more resources were likely ordered and subsequently assigned to each fire in each fire day at higher PLs in all GACCs (Figure 3).

Comparing daily resource ordering and daily resource assignments also shows that $\mathrm{CA}$ in general tends to order and assign more resources to each fire in each fire day than the other two GACCs, especially at higher PLs. This is consistent with the discoveries from previous studies e.g., [8]. The SWC has the lowest daily resource ordering amount and maintains the lowest daily resource assignment level at lower PLs. However, at higher PLs, both RMC and SWC show similar daily resource ordering and assignment patterns based on PC 1 and PC 2 (Figure 3). This suggests that SWC might have sent fewer resources to a fire in each day than both RMC and CA when the fire danger and the resource scarcity levels are both low (represented by lower PLs); on the other hand, CA seems to be much more risk averse and tends to order/assign more resources to a fire than the other two GACCs in each day.

\subsection{Resource Ordering Rule Supports}

Calculating and displaying association rule support in a "heatmap" (using the seaborn library [33] for python) reveals the probability that each resource category or each pair of resource categories may be ordered to a fire incident in the same fire day. The diagonal cells in the support heatmaps (Figure 4a) show the probabilities of ordering each individual resource category in each day. Engines are the resource type that is most likely to be ordered to a fire each day in all three GACCs under both high and low PLs. The likelihood of ordering at least one engine to a fire incident during a fire day is between $40 \%$ to $68 \%$ in all tested GACCs and under both PLs. Helicopters are the second most likely ordered resource type in CA and RMC (30 to 39\%), but not in SWC, which is more likely to order 
a crew (e.g., 27\% support at lower PLs and 29\% at higher PLs) than a helicopter (13\% at lower PLs and 22\% at higher PLs). Both CA and RMC also show a higher likelihood of ordering other aerial resources such as airtankers or fixed-wing planes than SWC (Figure 4). Instead, SWC is more likely to order water tenders (16\% support at lower PLs or $17 \%$ support at higher PLs) than RMC ( $9 \%$ or $10 \%$ support at lower or higher PLs).
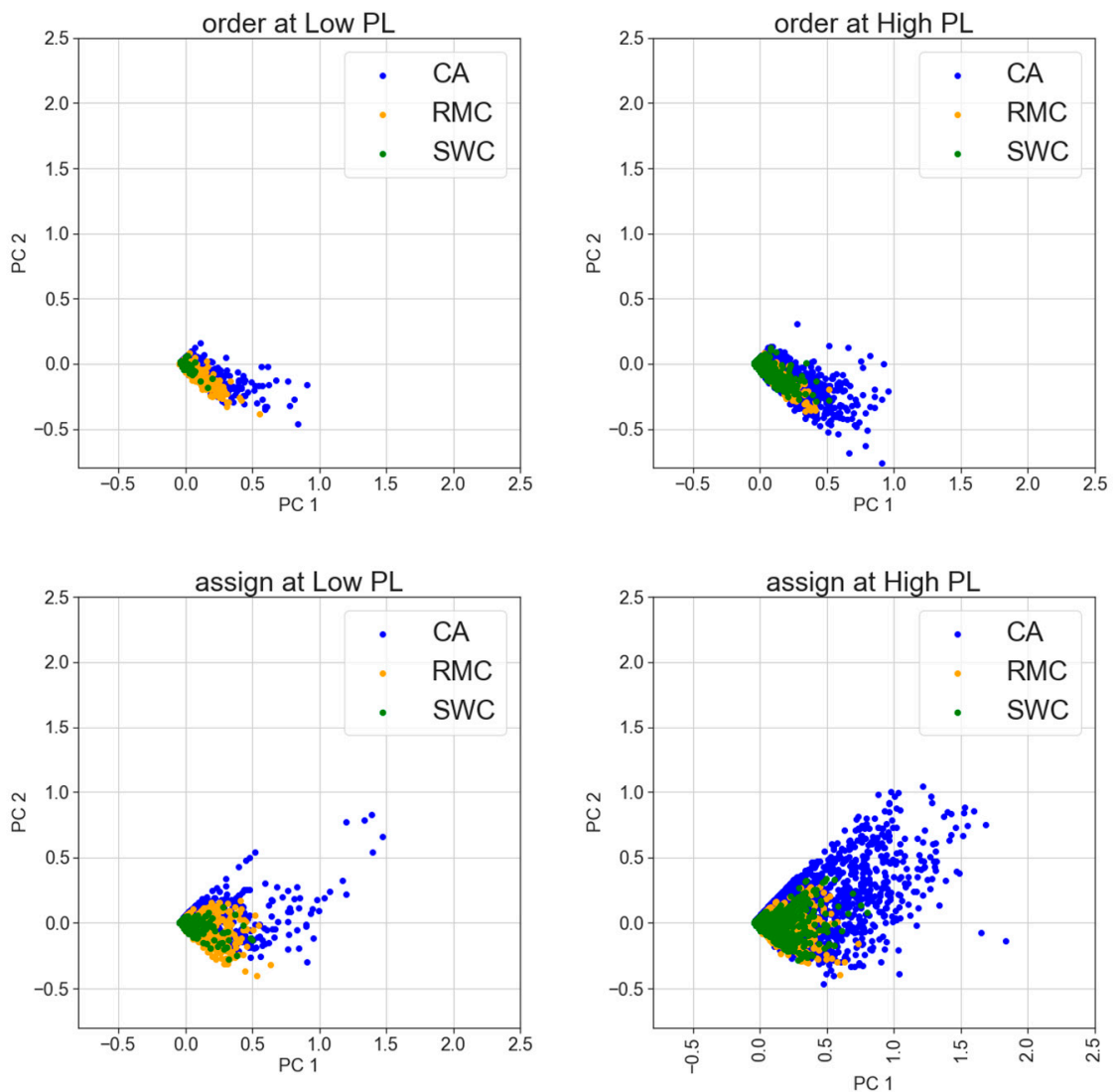

Figure 3. Daily resource order and assignments in three GACCs at low or high PL levels. x-axis represent principle component one (PC 1); y-axis represents principle component two (PC 2).

The most frequently ordered pairs of resources also show similarities across GACCs and between PLs (Figure 4a). For example, the engine/crew pair were most likely to be ordered in CA (25\% support at lower PL and 23\% at higher PL), which could be simply due to the abundance of both resource categories in California [17]. Other resources that were highly likely to be ordered in pairs in CA include engine/water tender, engine/dozer, engine/helicopter, airtanker/helicopter, and airtanker/fixed-wing. In RMC, the support for engine/crew, airtanker/fixed-wing, and helicopter/fixed-wing pairs are the highest for both high and low PLs. In SWC, engine/crew and engine/water tender are the two most likely ordered resource pairs at both high and low PLs. One interesting discovery is that at higher PLs, the likelihood that a fire in the SWC will order airtanker/fixed-wing or helicopter/crew pairs is tripled or almost doubled when compared with their orders at lower PLs.

\subsection{Resource Assignment Rule Supports}

Suppression resource daily assignment (Figure $4 \mathrm{~b}$ ) reflect the cumulative effects of daily resource ordering less demobilization. Observation of the association rule support heatmaps (Figure 4) shows that the assignment support of many single resource types or pairs of resources types often are not substantially different between high and low PL, although some differences do exist. For example, engines, crews, and helicopters are the single resource types most likely to be assigned to fire suppression in all three GACCs at both PLs, except at lower PLs in SWC, in which water tender replaces helicopter as the 
third most likely assigned single resource category. The engine/crew combination is the most likely assigned resource pair to each fire in each day for all GACCs at both high and low PLs. However, the second most likely assigned resource pair varies between GACCs and PLs, i.e., engine/water tender in CA, engine/helicopter in RMC, and engine/water tender at low PL and engine/helicopter at high PL in SWC.
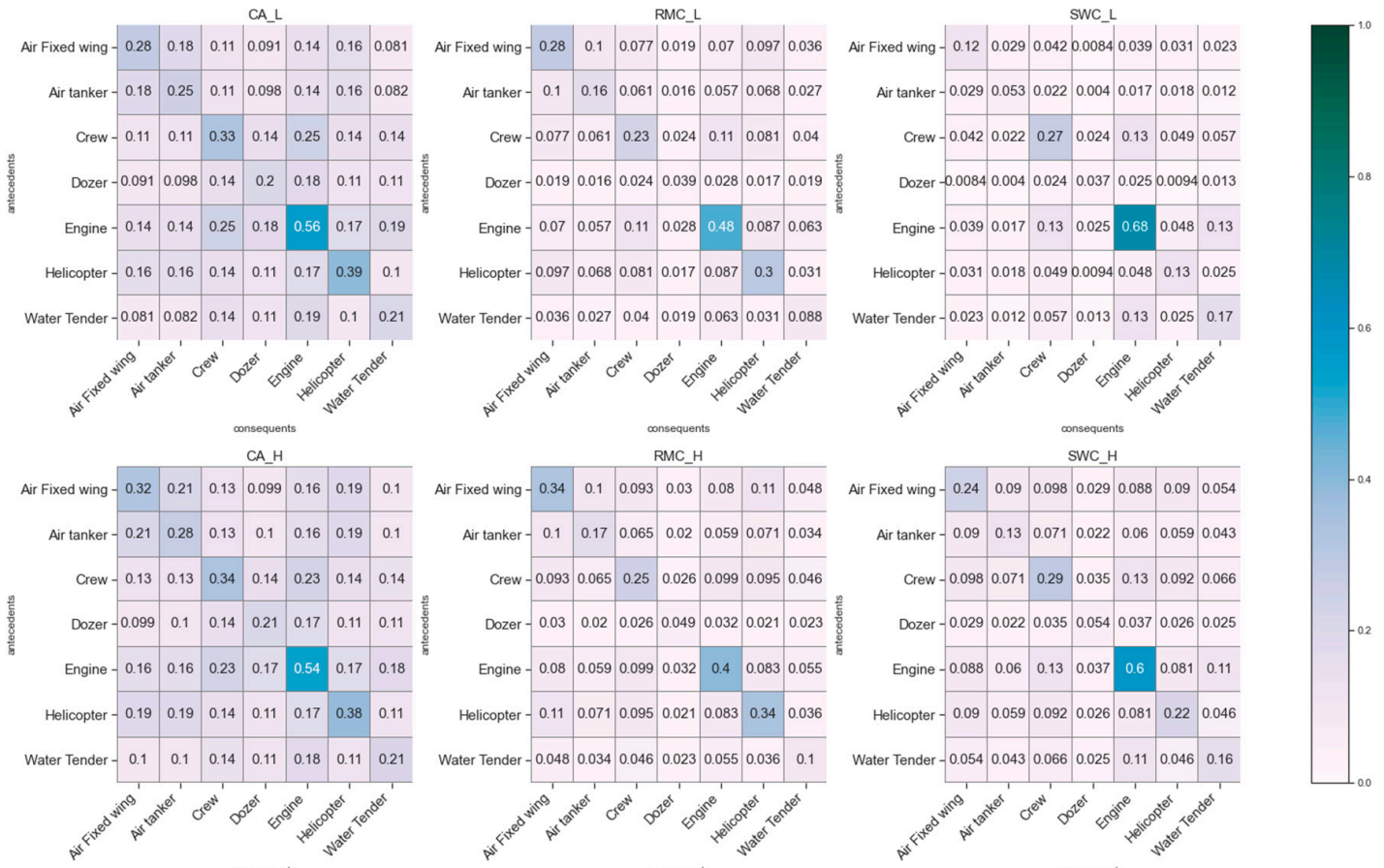

(a): pairwise daily order support
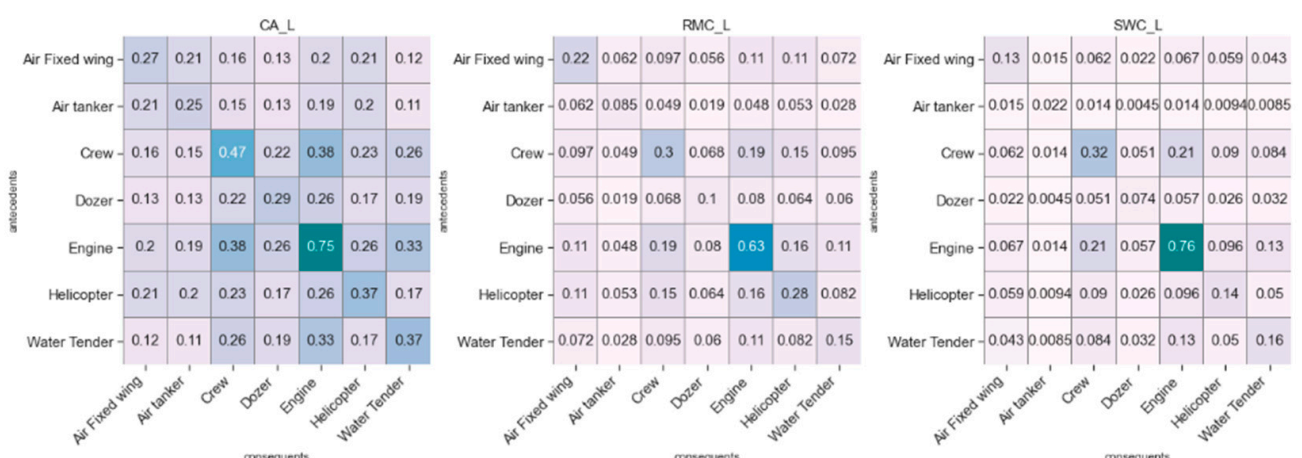

CA_H

RMC_H
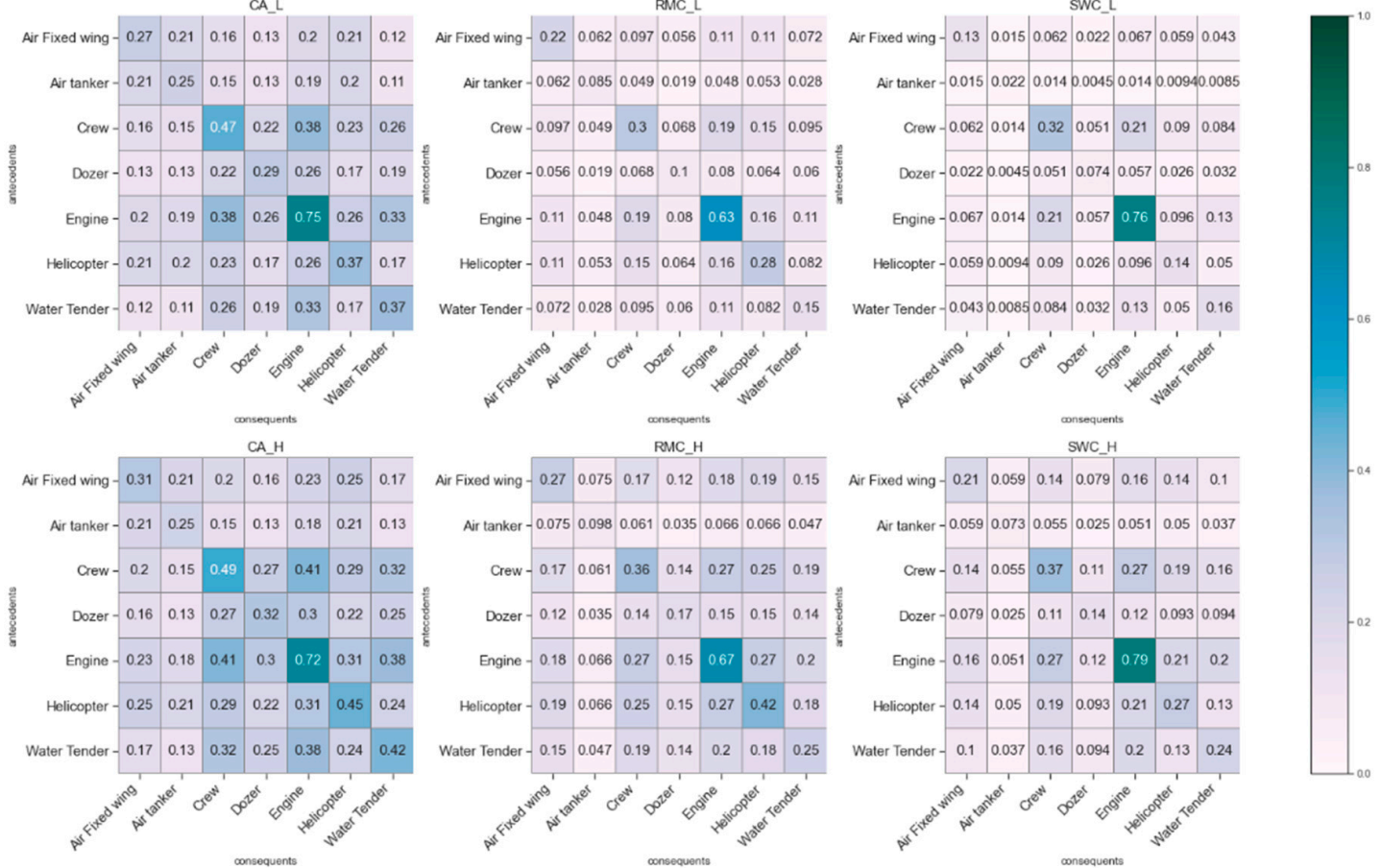

(b): pairwise daily assignment support

Figure 4. Support heatmaps for: (a) daily resource ordering and (b) daily resource assignments for three GACCs at both high and low PLs. 
CA shows overall a substantially higher probability of having paired resources assigned to each fire in each day, which is true even for resources that were not commonly paired in other regions. For example, we typically see a low probability of using both an airtanker and dozer together in all GACCs on the same fire day. However, the assignment association rule supports for the airtanker/dozer pair in CA are around 13\% at both PLs, while the support for the same pair in RMC is only 1.9\% at lower PLs and 3.5\% at higher PLs, and in SWC, it is as low as $0.4 \%$ at lower PLs and $2.5 \%$ at higher PLs.

\subsection{Resource Ordering Rule Confidences}

Resource ordering association rule confidence heatmaps (Figure 5a) display the conditional probability of ordering the set of consequent resources if the set of antecedent resources is ordered. Our study focuses on pairwise resource associations, in which a single resource category is included in the antecedent resource set and the consequent resource set. Each row of the heatmap displays the confidences of all association rules sharing the same antecedent resource type (Figure 5). In general, a lighter colored row in Figure 5a (lower confidences) indicates that a resource type is often ordered independently without the other resources; in other words, the consequent resource types are less likely to be ordered when the antecedent resource (one for each row) is ordered during a fire day. In contrast, a darker colored row in Figure 5a (higher confidences) represents the case that when an antecedent resource type is ordered, we can expect a high likelihood of consequent resource types being ordered on the same day. Comparing the seven general resource categories, engines were more likely to be ordered alone, while dozers were often ordered together with other resources (Figure 5). This is consistent with descriptions from [17], in which it indicates that dozers were often followed by hand crews to either finish the fire line, manage burn out based on dozer lines, hold the fire using dozer lines, or combat spot fires across dozer lines.

For aerial resources, order association rules with an airtanker as the antecedent often show higher confidences. When an airtanker was ordered, there is high confidence that either fixed-wing aircrafts, helicopters, crews, or engines would also be ordered together in the same day. Compared with airtankers, helicopters have much lower probabilities of being ordered together with other resource categories (e.g., their ordering association rules' confidence is mostly $\leq 50 \%$, shown in Figure 5a). This indicates helicopters are more likely to work independently than airtankers and other fixed wing aerial resources.

In contrast to association rule support, association rule confidence is usually not symmetric. For example, the confidence of the crew $\Longrightarrow$ engine order association is $74 \%$ at low PL and $69 \%$ at high PL in CA. It indicates that when crews were ordered, there is about a $70 \%$ chance that at least one engine would also be ordered at the same day for the same incident in California. However, the confidences of the engine $\Longrightarrow$ crew ordering associations are typically less than $50 \%$ at both PLs in CA, which means engines are much more likely to be ordered without crews than with crews in California during each fire day. The association between engine and dozer orders shows another example of asymmetric association confidence. Compared with the high confidences of dozer $\Longrightarrow$ engine order associations, e.g., around $70 \%$ in RMC and SWC, around $84 \%$ and $90 \%$ in CA, the engine $\Longrightarrow$ dozer order association is substantially lower, i.e., only from $3.7 \%$ to $8 \%$ in RMC and SWC, and slightly above $30 \%$ in CA. Thus, it is common for managers to order engine(s) when a dozer is ordered, but it is less common for them to order any dozer when an engine is ordered. 

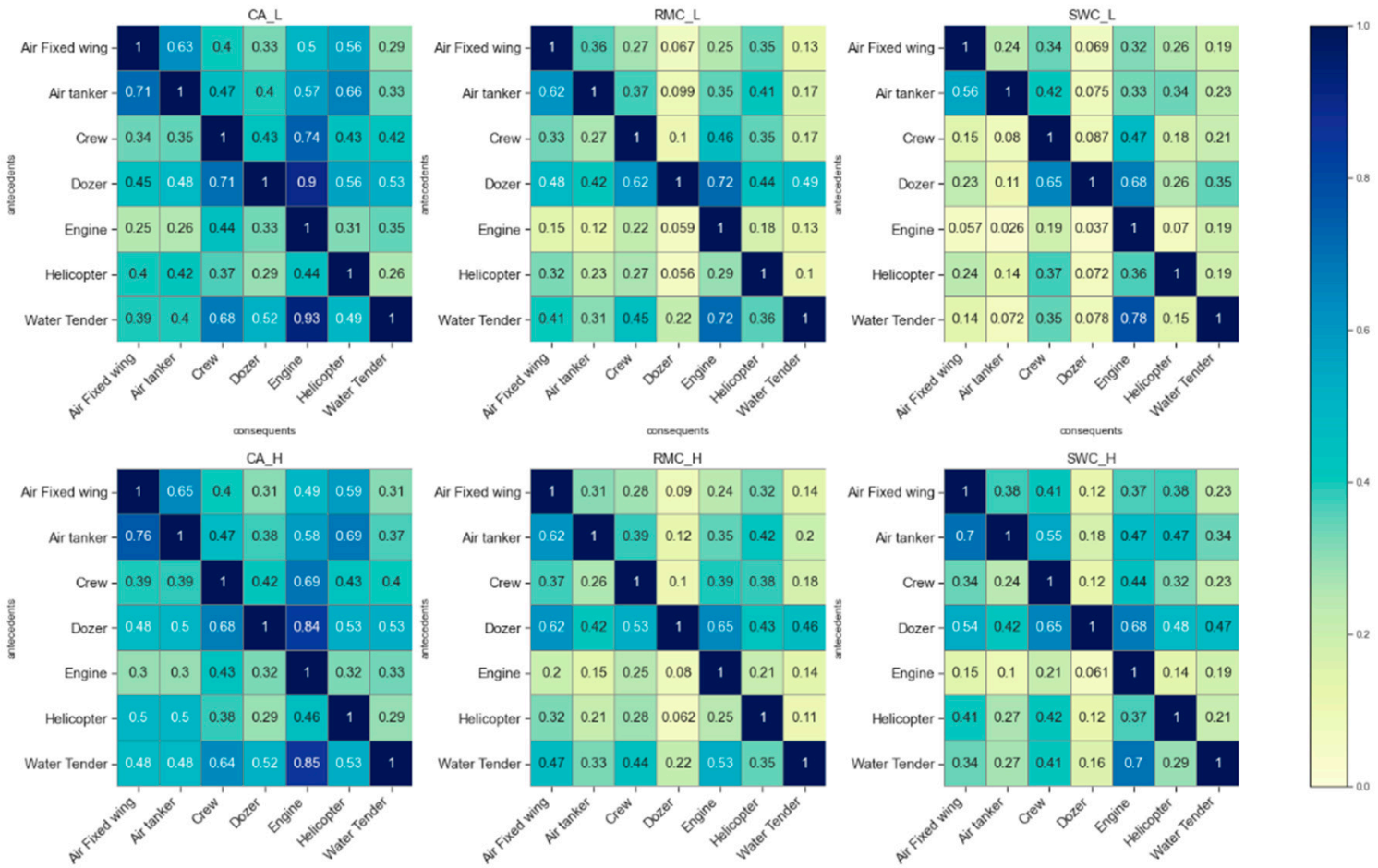

(a: pairwise daily-order confidence)
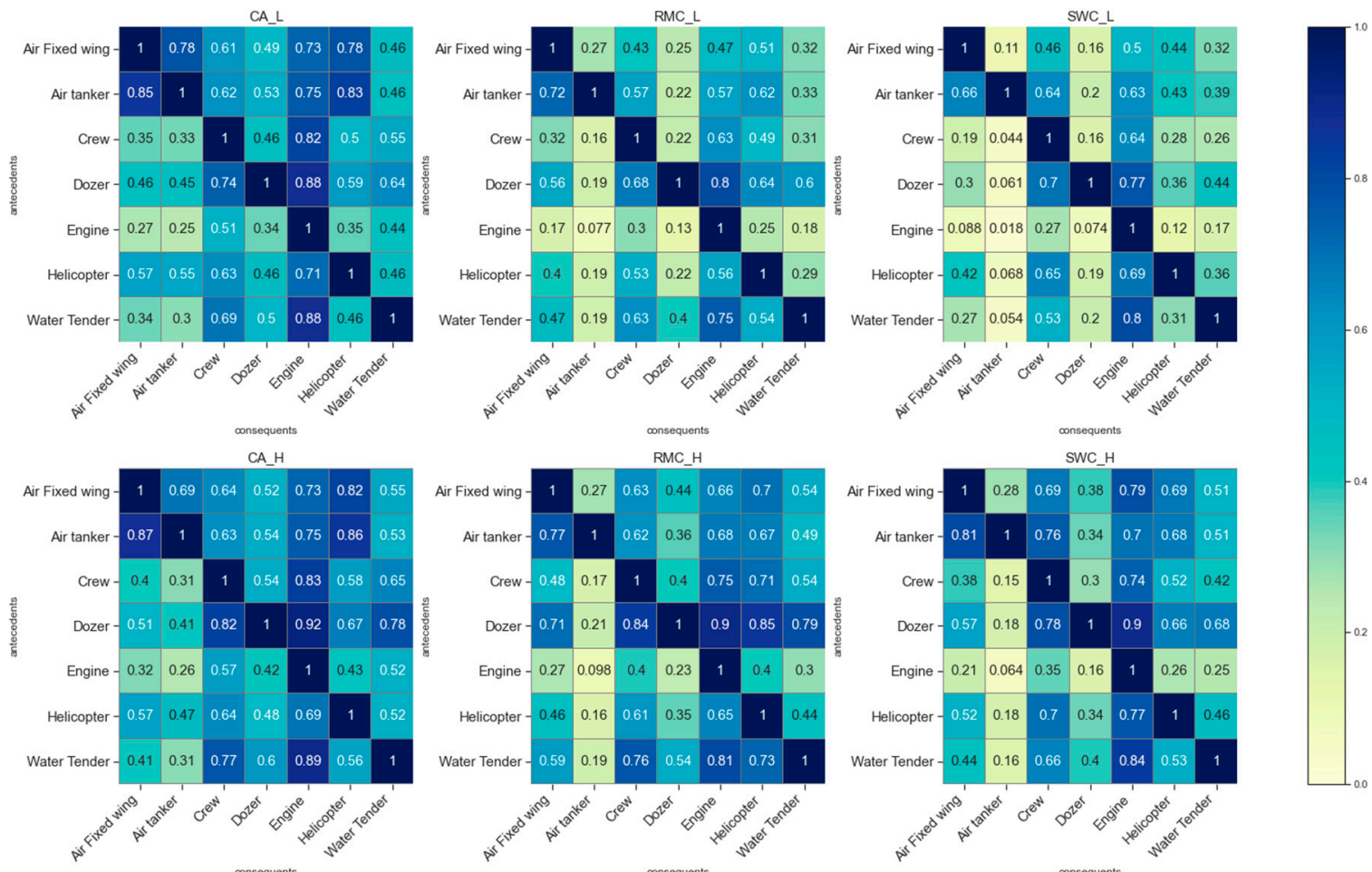

(b: pairwise daily-assignment confidence)

Figure 5. Confidence heatmaps for: (a) daily resource ordering and (b) daily resource assignments for three GACCs at both high and low PL, i.e., CA_H represents GACC California (CA) at high PL, CA_L denotes the same GACC at low PL.

\subsection{Resource Assignment Rule Confidences}

Unsurprisingly, we find similar patterns in the association rules for daily resource assignments (Figure $5 b$ ) and daily resource orders (Figure 5a). The highest confidences 
between ground resource assignments are still found in dozer $\Longrightarrow$ engine and water tender $\Longrightarrow$ engine associations at both PLs. For example, if any water tender was assigned to a fire, the likelihood for an engine being assigned to the same fire in the same day is about $90 \%$ in CA, 75\% at low PL, and $81 \%$ at high PL in RMC, and $80 \%$ at low PL and $84 \%$ at high PL in SWC, which means there is only about a $10 \%$ chance in CA and less than a $25 \%$ chance in the other two GACCs for water tender to work on a fire during a fire day without an engine.

Higher confidences can be found for most rules at high PL than at lower PL in all three GACCs. This pattern is more apparent in the assignment confidence heatmap (Figure 5b) than in the ordering confidence heatmap (Figure 5a) due to cumulative resource requests over multiple days. For example, after a crew is assigned, it may stay on a fire for up to 14 days, and resources ordered on other days may end up working together with that crew during their overlapping shifts. Higher assignment association confidence at higher PLs could be attributed to the higher resource collaboration requirements of more severe fire situations, longer shift lengths on large fires, or simply because more resources were assigned to the same fires at higher PLs.

Airtankers are a resource type that has unique assignment patterns. For the most part, they are nationally owned strategic resources that may be ordered, dispatched, and reassigned to multiple fires within the same day [1,7]. Unlike the other resource types examined in this analysis, the assignment associations with an airtanker as the consequent resource often show lower confidences than the corresponding ordering rules (comparing Figure 5a,b). Using the airtanker and crew association as an example, after an airtanker was ordered on a fire day, it could be reassigned to a different fire in the same day or in the next day while crews are still working on the same fire to finish their 14-day shift. This would lead to lower confidence for the crew $\Longrightarrow$ airtanker assignment rule than the corresponding crew $\Longrightarrow$ airtanker ordering rule. In fact, the crew $\Longrightarrow$ airtanker assignment rule confidences are much lower and vary dramatically between GACCs and PLs, i.e., a little bit above $30 \%$ in CA, about $16 \%$ or $17 \%$ in RMC, and only $4.4 \%$ in SWC at lower PLs and 15\% at higher PLs. It indicates: (1) crews often work on fires independently without airtanker support during each fire day; (2) crews in California are much more likely to work together with an airtanker than crews in the other two GACCs; (3) crews rarely work with airtankers in the SWC at low PL, but that probability increases four times at high PL. In the opposite direction, airtanker $\Longrightarrow$ crew assignment associations consistently have much higher confidences, e.g., between $57 \%$ and $76 \%$ in all GACCs. It indicates that the probability of having an airtanker working on a fire without an on-the-ground crew is relatively low (24\% to $43 \%$ ) in all GACCs, which is consistent with discoveries from [26].

\subsection{Confidence vs. Support}

Individual heatmaps display either association rule confidence or support (Figures 4 and 5). In this section, we plot the two indicators together for selected rules using the matplotlib.pyplot library [34] from python. To improve the readability of those graphs, we select the highest confidence rule out of all the rules that share the same antecedent resource type (we call it "most confident" rule of the antecedent resource) and graph the confidence and support of those rule as "bubbles" in Figure 6. The position of the center of each circle is determined by both the confidence and support for the corresponding rule; the size of each circle is proportional to the support of the antecedent suppression resource.

Resource collaboration patterns can be observed through those plots (Figure 6). For example, the support for engines (proportional to the bubble sizes with engine as the antecedent resource) is always the highest in all GACCs at both PLs for either resource order or assignment. The engine/crew pair is among the most likely pair of collaborators according to their assignment rule supports (Figure 6b). Again, the confidences for engine $\Longrightarrow$ crew order and assignment are always much lower than the opposite crew $\Longrightarrow$ engine order and assignment. In fact, the engine $\Longrightarrow$ crew order and assignment always have the lowest confidences among all the most confident rules plotted (Figure 6). Within other 
rules with an engine as the consequent resource, both the dozer $\Longrightarrow$ engine and water tender $\Longrightarrow$ engine order and assignment rules have high confidences. For aerial resources, the most confident rules with the fixed-wing aircraft as antecedent are either with airtanker, helicopter, engine, or crew as the consequent resources. This indicates that fixed-wing aircraft are likely ordered and assigned to support a variety of resource types including helicopters, airtankers and ground resources; this discovery is also consistent to the findings from [26].

Within the selected most confident rules, the support of each rule is not always correlated with the confidence of that rule. We note that the supports for the selected resource ordering rules (Figure 6a) are within a narrow range in all GACCs, e.g., around $20 \%$ in CA, and less than 20\% in RMC and SWC, but their confidences vary substantially, e.g., around $40 \%$ to $95 \%$ in CA, and $20 \%$ to $80 \%$ in the other two GACCs. For resource assignments (Figure $6 \mathrm{~b}$ ), we find slightly wider support range for the selected rules, e.g., around $20 \%$ to $40 \%$ in CA, and less than $30 \%$ in the other two GACCs; the confidence ranges of those rules are still much wider, e.g., about $40 \%$ to $95 \%$ in CA and $20 \%$ to $80 \%$ in the other two GACCs. Comparing the rules with similar support but lower confidence indicates that the antecedent resource would more likely be ordered or assigned independently from the other resource types. Engines and helicopters consistently fall into this category, followed by fixed-wing airplanes. The other resource types such as dozers, airtankers, and water tenders tend to require more collaborations from other resource types.

\subsection{Association Rules between Resource Subcategory Assignments}

Analysis of the assignment of resource subcategories (Table 1) reveals some finer-scale patterns in daily suppression resources collaboration. We first display association rules with multiple crew subcategories, including crew teams, type 1 crew, initial attack (IA) crew, or type 2 crew as the antecedent items, and with engine subcategories including engine teams, structure engines, or wildland engines as the consequent items. To make the graph simpler to read, we only list those subcategory assignment rules with a support $>5 \%$ and a confidence $>50 \%$ (Figure 7). Test results show that the type $1 \mathrm{crew} \Longrightarrow$ wildland engine assignment associations often have the highest confidences (around $80 \%$ ) in RMC and SWC at both PLs. In CA, the crew team $\Longrightarrow$ wildland engine association has the highest confidence (about $90 \%$ ), while the type $1 \mathrm{crew} \Longrightarrow$ wildland engine assignment associations still have above $80 \%$ confidence at both PLs. This figure also indicates that fires in CA were more likely to use a type $1 \mathrm{crew}$ (represented by the large circles in Figure 7) than a type 2 crew or IA crew, which is different from the other two GACCs, as both RMC and SWC show a similar likelihood of using type 1, 2, or IA crews. In CA at higher $\mathrm{PL}$, we found similar confidence of using wildland engine to support either type 1, 2, or IA crews. However, in RMC and SWC, type 1 crews have a higher likelihood of being assigned together with wildland engines than the less trained type 2 crews.

We also studied airtanker or fixed wing airplane subcategories, including small airtankers, large airtankers, lead planes, tactical planes, cargo planes, infrared planes, passenger planes, recon planes, or smokejumper planes as either the antecedent or consequent resources (Figure 8). For simplicity, we only display those assignment rules with support $>1 \%$ and confidence $>50 \%$. We find more association rules meet those support and confidence thresholds at higher PLs than at lower PLs for all three GACCs. In fact, at lower PLs, we cannot find airtanker or fixed-wing aerial assignment associations in SWC that meet the above support and confidence thresholds, which indicates that those resources are less commonly used in SWC at lower PLs. Results also reveal that small airtanker and fixed-wing tactical plane are the two most used fixed-wing aerial resource types in CA. At lower PLs, if one of the two types are assigned, we would likely see the other type being assigned at the same day. In CA, a small airtanker is much more likely to be assigned to a fire during a fire day than a large airtanker (reflected by the bubble size in Figure 8), potentially because the California Department of Forestry and Fire Protection (CAL FIRE) owned many small airtankers that are dedicated for CA only. Both large airtankers and 
small airtankers typically work together with fixed-wing tactical planes or fixed-wing lead planes. Large airtankers very likely work with small airtankers in the same fire day in CA and RMC at both PLs (e.g., about 80\% in CA and 70\% in RMC), or in SWC at higher PLs (about 60\%), but not in SWC at lower PLs.
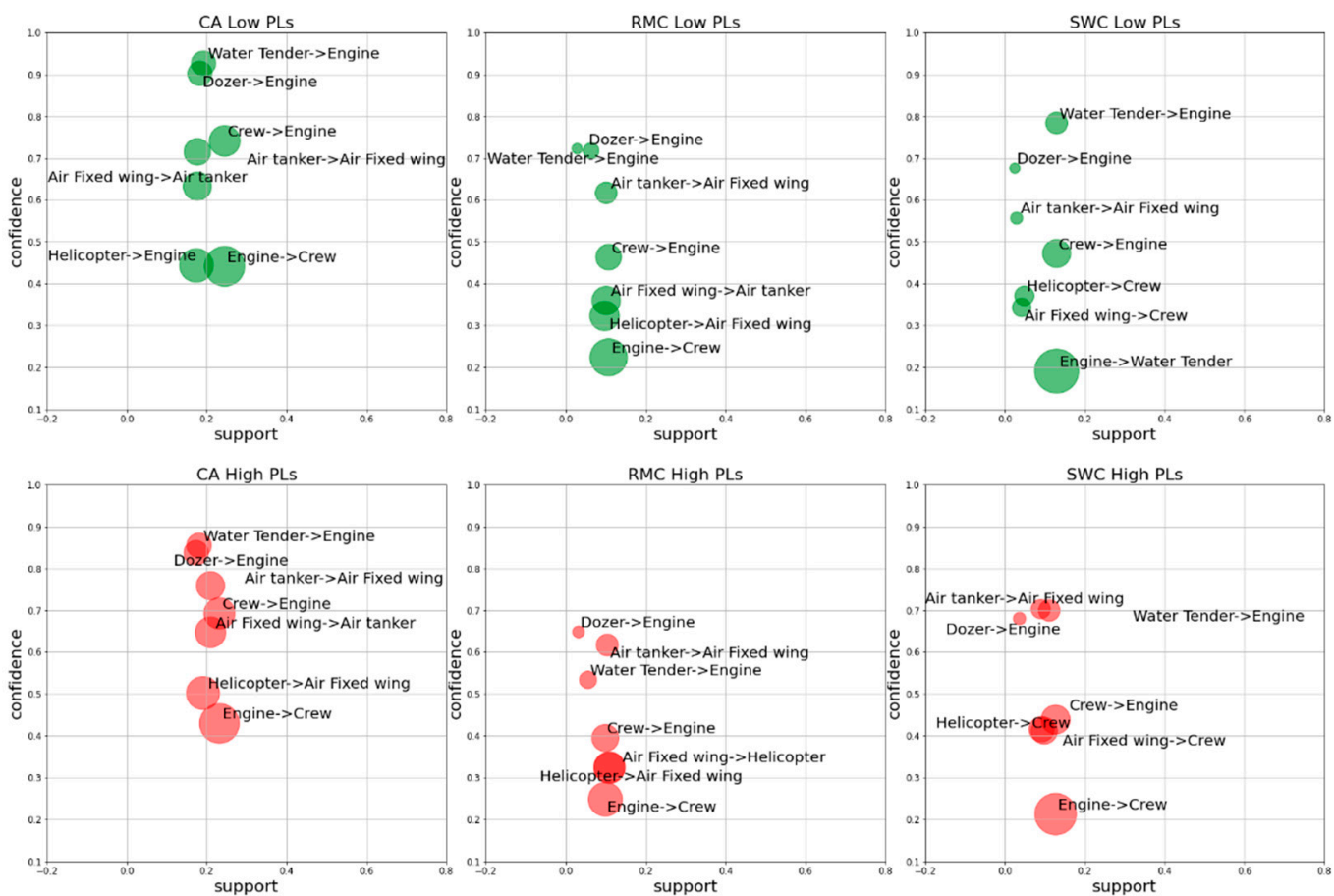

(a: pairwise daily-order confidence vs. support)
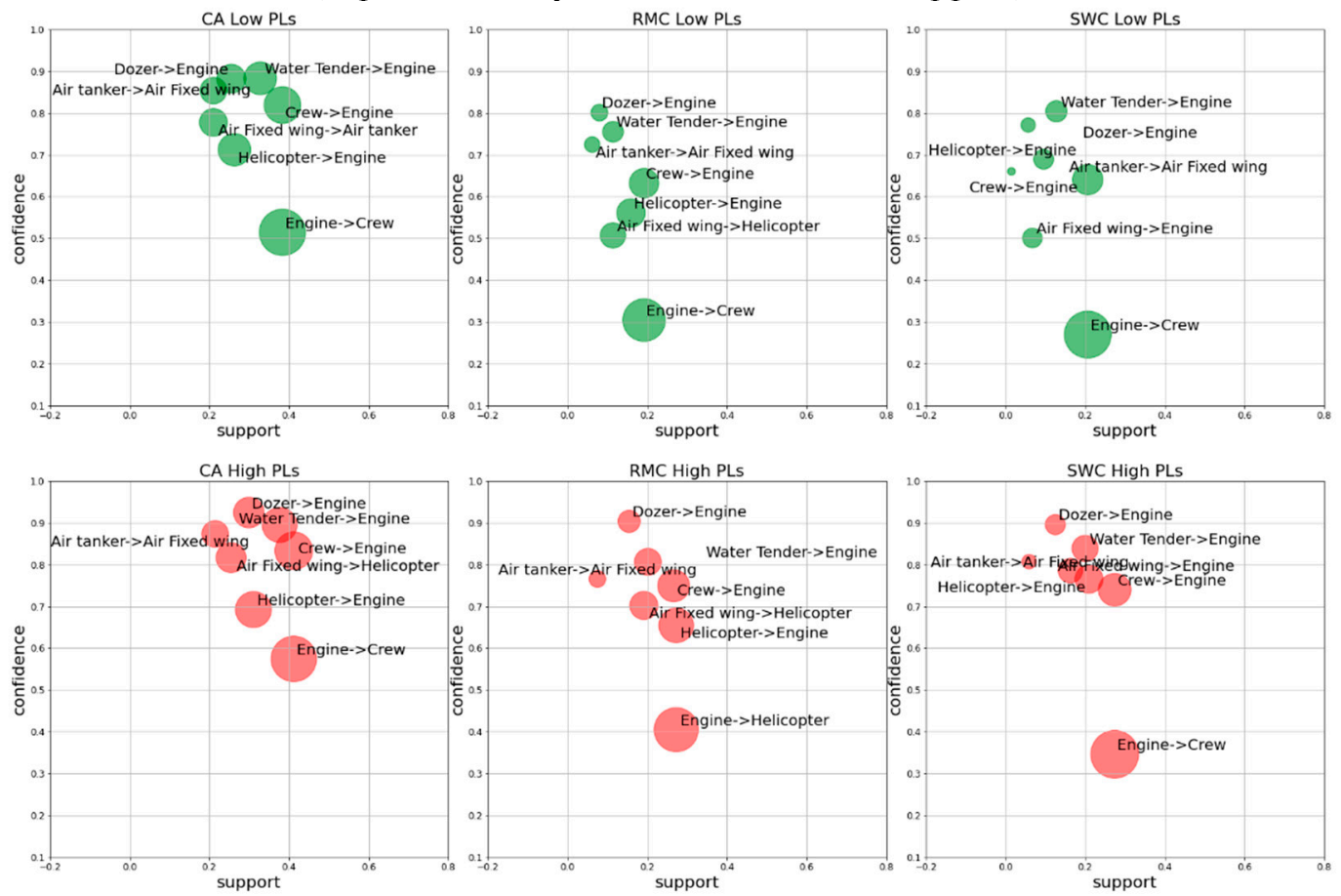

(b: pairwise daily-assignment confidence vs. support)

Figure 6. Bubbled scatter plots displaying the confidence and support of selected rules for both resource order and resource assignment. For each resource type as antecedent, only the rule with the highest confidence is graphed. Circle size is proportional to the support of the corresponding antecedent resource. 

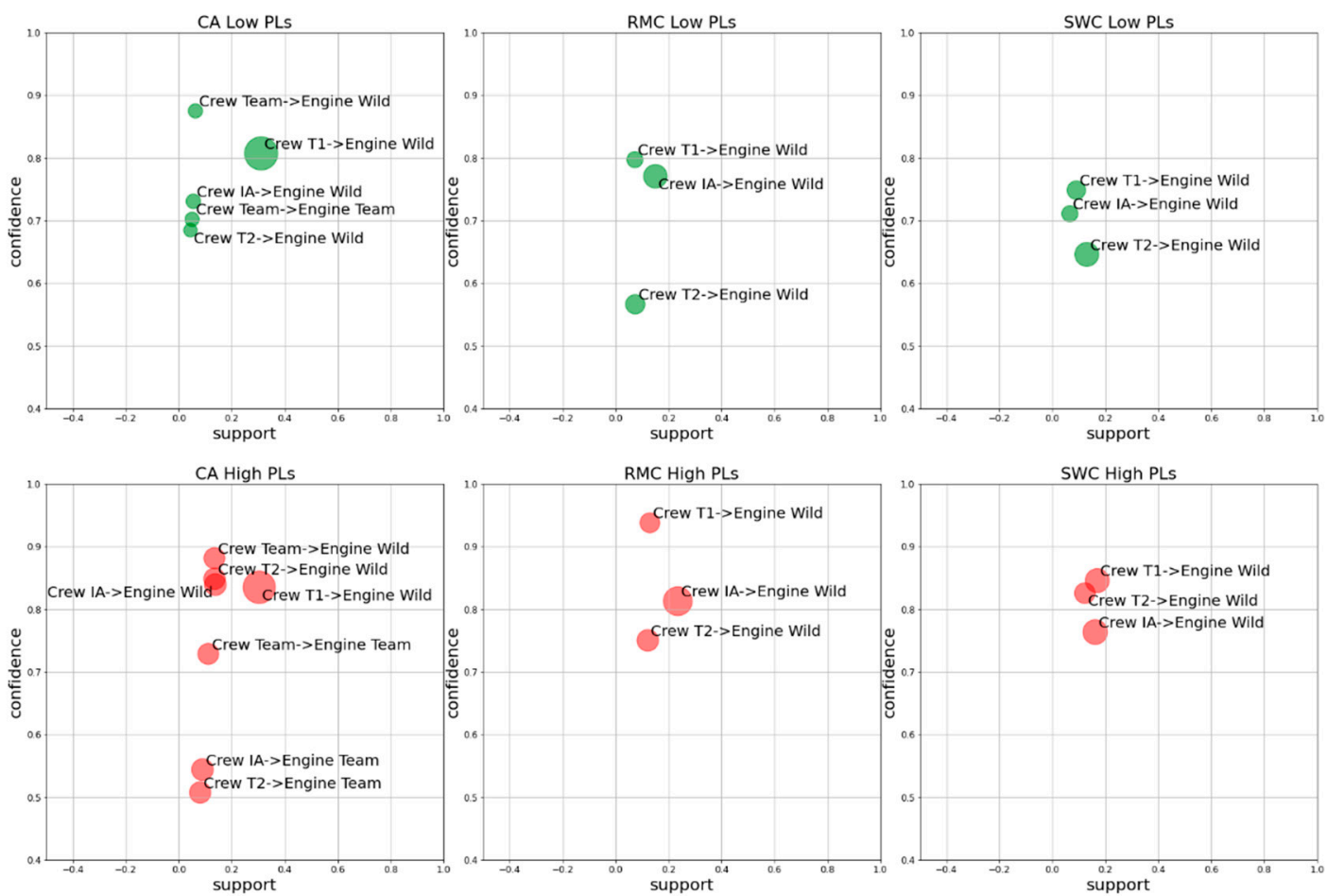

Figure 7. Association rules (support $>5 \%$ and confidence $>50 \%$ ) from crew subcategories to engine subcategories for daily assignments in three GACCs at two PL levels. Engine Wild: wildland engine; Crew T1: type 1 crew; Crew T2: type 2 crew; Crew IA: initial attack crew.
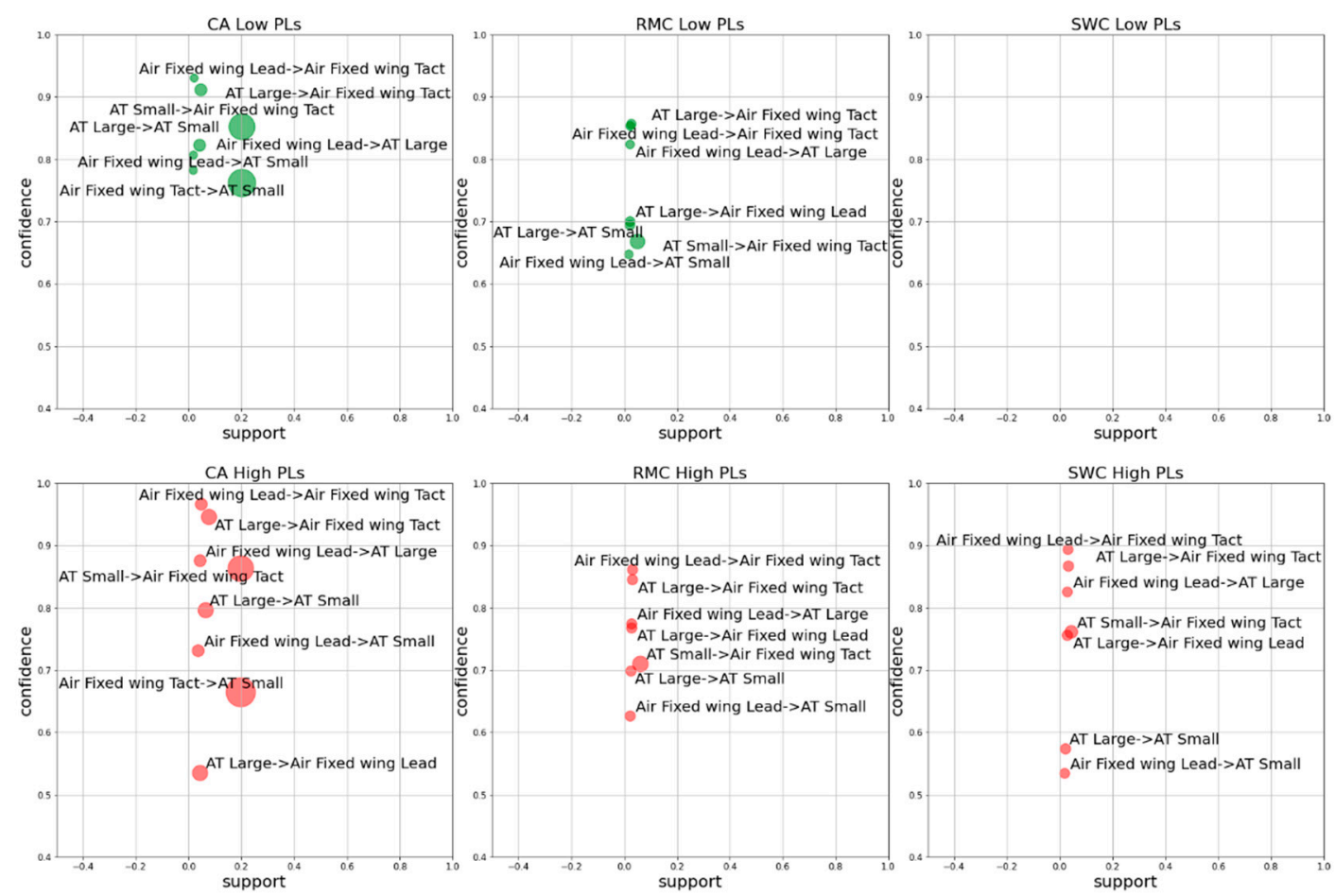

Figure 8. Association rules (support $>1 \%$ and confidence $>50 \%$ ) between fixed-wing aerial resource (included airtankers) subcategories for daily assignments in three GACCs at two PL levels. AT Large: large airtanker; AT Small: small airtanker; Lead: lead plane; Tact: tactical plane. 


\section{Discussion and Conclusions}

This study implemented the PCA and ARA methods to study fire suppression resource ordering and assignment patterns using the 2016 to 2018 ROSS data on filled suppression resource requests. We studied three GACCs in the western US at both higher and lower PLs. ARA identifies the frequent co-ordering or co-assignment of multiple resources during each fire day and helps us understand how resources interact together and whether they can work synergistically. We calculated supports for single resource categories or pairs of resource categories that were ordered or assigned to each fire during each day. We calculated the confidences of association rules between pairs of resource categories (or subcategories). Our analysis quantitatively revealed some daily suppression resource order and assignment patterns based on existing empirical data; many of them are consistent with the qualitative descriptions from $[17,26]$ and previous research findings.

Our study found that engines, crews, and helicopters were the most frequently ordered and assigned single resource types in each fire day for each fire. Engines were also most likely to be ordered or assigned independently without the need to collaborate with other resources. The common use of engines is potentially due to its abundance across the nation [35], flexibility of achieving a variety of suppression objectives, including fireline construction, dozer line cleanup, crew and equipment transportation, point protection, burnout, etc. In contrast, dozer, water tender or airtankers were more likely ordered and assigned together with other resource categories.

Most unsupervised learning methods such as PCA and ARA are good at discovering patterns by mining unlabeled empirical data. Those discoveries could be used to configure hypotheses, identify correlations, and predict future outcomes. However, unsupervised learning does not typically analyze the causes behind many of the identified patterns, nor prove or reject certain identified hypotheses. Additional research is necessary to further investigate the causal relationships behind those discoveries.

Here are some examples of potential future investigations based on the discoveries from the ARA. Aerial resource orders and assignments in SWC at lower PLs are much lower than the other two GACCs. Several reasons could lead to this, for example, fewer natural water sources available for aerial resource use, higher cost of aerial resource use (especially if the retardant system were used), relative fewer values at risk comparing with the other regions, fire management policy, or other challenges including the "density altitude" as described in [17]. However, we also noticed at higher PLs that the probability of using aerial resources increases substantially in SWC. One hypothesis is that at higher PLs, managers may be more aggressive in attacking the fire away from roads to reduce the total amount of fire on the landscape; therefore, they might be less concerned about the higher cost of using aerial resources and they might rely more on retardant instead of natural water sources to take advantage of the speed and flexibility of aerial resources. Further studying this pattern in SWC could lead to better understanding of the impact of water source availability, cost, values at risk, and altitude affecting the use of helicopters, fixed wings, and airtankers in comparison of using ground-based resources such as water tenders.

Discoveries from this study also suggested the need to further investigate the potential collaboration or substitution between different types of suppression resources. For example, dozer $\Longrightarrow$ engine order and assignment rules have much high confidences in all regions at both PLs than the opposite engine $\Longrightarrow$ dozer order and assignment rules. Future research could be designed to study how each resource type may be used for different tasks but collaboratively to achieve common suppression objectives. Engines and dozers may also be suitable for different road conditions and raise different environmental concerns. Another future research direction could include extending the ARA analyses to study resource ordering and assignment patterns under different fire situations, i.e., for different fire size classes, durations, incident management team types, fire suppression stages (as suggested by [23]), etc.

Comparing the three GACCs studied, managers in CA were more likely to use multiple types of suppression resources together as described by other past studies [8,36]. CA is also 
more likely to use "teams" formed by either multiple engines (engine team) or multiple crews (crew team). Given its higher population density in CA, there is generally more concerns of fire risk in this region. Higher risk creates a demand for more resources. Plus, there may be more resources available in California than the other two GACCs. Abundant supplies make it easier for CA to coordinate multiple resource types during fire suppression, which is reflected by higher supports and confidences of suppression resource ordering and assignment rules. Future research may need to collect additional information such as fire suppression objectives and whether they have been better achieved in CA to study the potential return of investment by using multiple resource types together. Future studies may also help us understand how factors such as topography, fire season, fuel conditions, or climate factors [37] would influence the efficiency of suppression resource collaborations.

Studying the daily fire incident level resource ordering and assignments data helps reveal some interesting patterns of suppression resource use and collaboration. However, to more thoroughly study the patterns and efficiency of fire suppression decisions, we may need to collect finer-scale fire suppression data at the individual fireline level and synchronize different types of data at finer temporal scales, e.g., hourly. One reason is many of the key events and decisions occurred during large fire suppression, i.e., retardant drop, line breaching, and fire spotting, are associated with fire behaviors and suppression decisions at specific time and locations. Collecting finer scale spatial and temporal data is critical in helping us conduct in-depth studies in fire suppression resource use and its effectiveness. This would require improving the tracking of individual suppression resources movement, recording and predicting real time weather near key fire control locations, as well as conducting detailed and consistent documentation of fire suppression objectives at different spatial scales, e.g., at incident, division, and fireline levels.

Author Contributions: Conceptualization, Y.W., M.P.T., E.J.B. and J.B.; data curation, Y.W. and E.J.B.; formal analysis, Y.W.; funding acquisition, D.E.C.; investigation, Y.W., M.P.T., E.J.B., D.E.C. and J.B.; methodology, Y.W., M.P.T., E.J.B. and J.B.; project administration, D.E.C.; resources, D.E.C.; validation, D.E.C.; visualization, Y.W., M.P.T. and J.B.; writing—original draft, Y.W., M.P.T. and E.J.B.; writingreview \& editing, Y.W., M.P.T., E.J.B., D.E.C. and J.B. All authors have read and agreed to the published version of the manuscript.

Funding: This research was funded by the joint venture agreement between Colorado State University and the USFS Rocky Mountain Research Station, grant number 19-JV-11221636-170.

Conflicts of Interest: The authors declare no conflict of interest. 
Appendix A

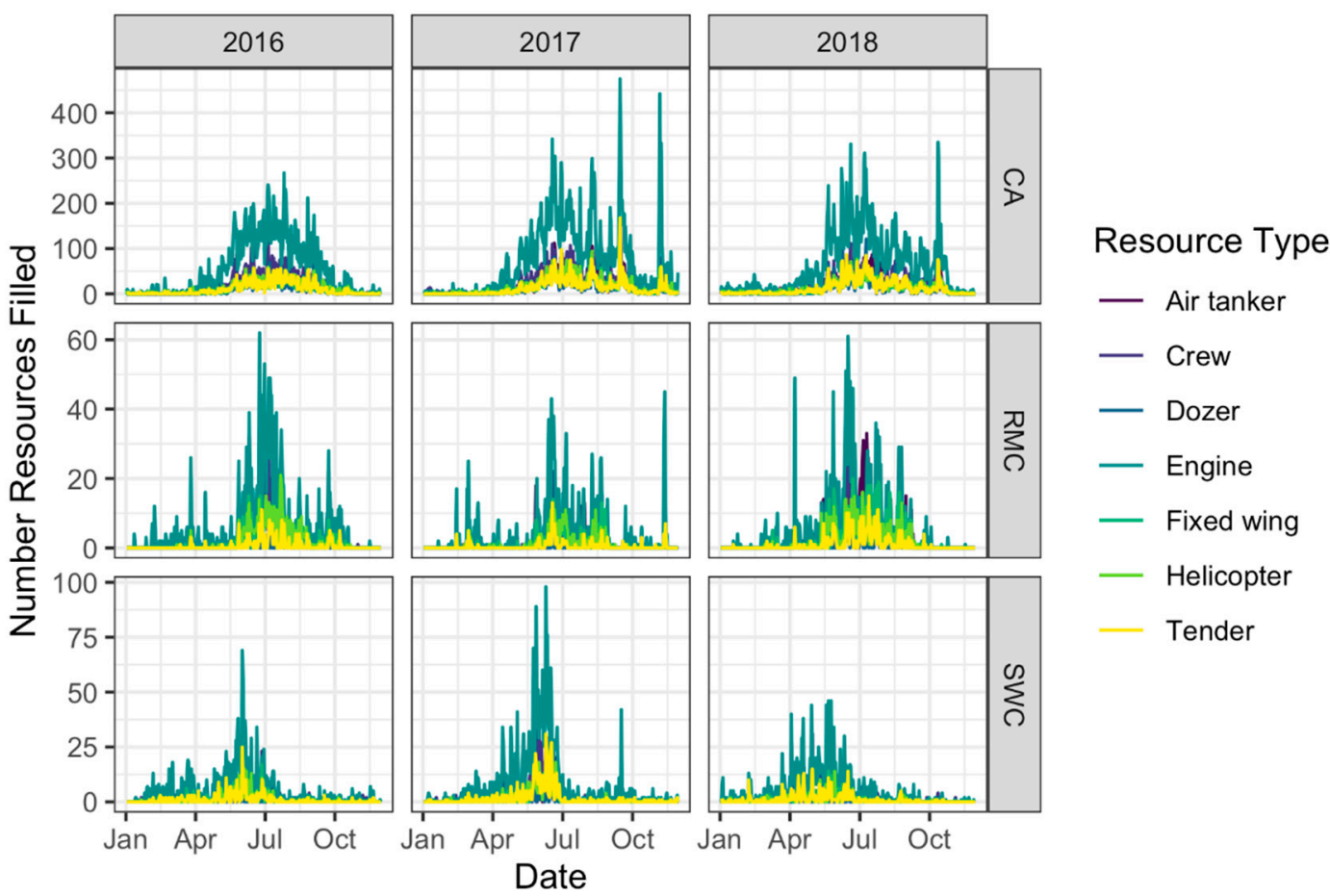

Figure A1. Number of resources ordered and filled during each day from 2016 to 2018 in the three GACCs tested.

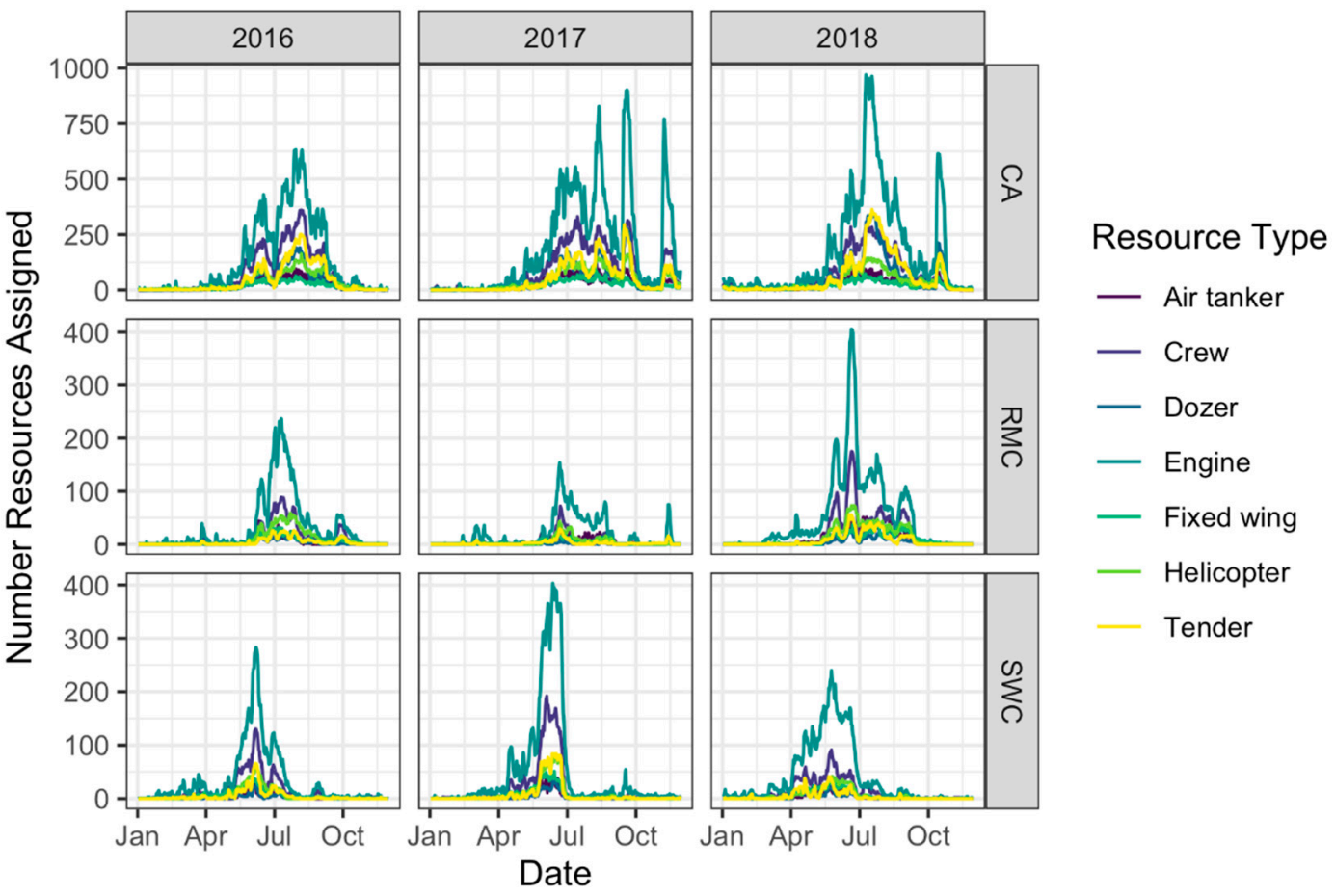

Figure A2. Daily number of resources assigned to all fires in the three GACCs from 2016 to 2018. 


\section{References}

1. Belval, E.J.; Stonesifer, C.S.; Calkin, D.E. Fire Suppression Resource Scarcity: Current Metrics and Future Performance Indicators. Forests 2020, 11, 217. [CrossRef]

2. Plucinski, M.P. Contain and control: Wildfire suppression effectiveness at incidents and across landscapes. Curr. For. Rep. 2019, 5, 20-40. [CrossRef]

3. Katuwal, H.; Calkin, D.E.; Hand, M.S. Production and efficiency of large wildland fire suppression effort: A stochastic frontier analysis. J. Environ. Manag. 2016, 166, 227-236. [CrossRef] [PubMed]

4. Duff, T.J.; Tolhurst, K.G. Operational wildfire suppression modelling: A review evaluating development, state of the art and future directions. Int. J. Wildland Fire 2015, 24, 735-748. [CrossRef]

5. Dunn, C.D.; Calkin, D.E.; Thompson, M.P. Towards enhanced risk management: Planning, decision making and monitoring of US wildfire response. Int. J. Wildland Fire 2017, 26, 551-556. [CrossRef]

6. Bayham, J.; Belval, E.J.; Thompson, M.P.; Dunn, C.; Stonesifer, C.S.; Calkin, D.E. Weather, Risk, and Resource Orders on Large Wildland Fires in the Western US. Forests 2020, 11, 169. [CrossRef]

7. Stonesifer, C.S.; Calkin, D.E.; Thompson, M.P.; Stockmann, K.D. Fighting Fire in the Heat of the Day: An Analysis of Operational and Environmental Conditions of Use for Large Airtankers in United States Fire Suppression. Int. J. Wildland Fire 2016, 25, 520-533. [CrossRef]

8. Hand, M.; Katuwal, H.; Calkin, D.E.; Thompson, M.P. The influence of incident management teams on the deployment of wildfire suppression resources. Int. J. Wildland Fire 2017, 26, 615-629. [CrossRef]

9. Jain, P.; Coogan, S.C.P.; Subramanian, S.G.; Crowley, M.; Taylor, S.; Flannigan, M.D. A review of machine learning applications in wildfire science and management. Environ. Rev. 2020, 28, 478-505. [CrossRef]

10. Sayad, Y.O.; Mousannif, H.; Moatassime, H.A. Predictive modeling of wildfires: A new dataset and machine learning approach. Fire Saf. J. 2019, 104, 130-146. [CrossRef]

11. Tehrany, M.S.; Jones, S.; Shabani, F.; Martínez-Álvarez, F.; Bui, D.T. A novel ensemble modeling approach for the spatial prediction of tropical forest fire susceptibility using LogitBoost machine learning classifier and multi-source geospatial data. Theor. Appl. Climatol. 2018, 137, 637-653. [CrossRef]

12. O'Connor, C.D.; Calkin, D.E.; Thompson, M.P. An empirical machine learning method for predicting potential fire control locations for pre-fire planning and operational fire management. Int. J. Wildland Fire 2017, 26, 587-597. [CrossRef]

13. Elia, M.; D’Este, M.; Ascoli, D.; Giannico, V.; Spano, G.; Ganga, A.; Colangelo, G.; Lafortezza, R.; Sanesi, G. Estimating the probability of wildfire occurrence in Mediterranean landscapes using Artificial Neural Networks. Environ. Impact Assess. Rev. 2020, 85, 106474. [CrossRef]

14. Thompson, M.P. Modeling Wildfire Incident Complexity Dynamics. PLoS ONE 2013, 8, e63297. [CrossRef] [PubMed]

15. Huber-Stearns, H.; Moseley, C.; Bone, C.; Mosurinjohn, N.; Lyon, K.M. An Initial Look at Contracted Wildfire Response Capacity in the American. West. J. 2019, 117, 1-8. [CrossRef]

16. Masarie, A.T.G.; Wei, Y.; Belval, E.J.; Thompson, M.P.; Oprea, I.; Tabatabaei, M.; Calkin, D.E. Valuating fire suppression risk data. App. Math. Model. 2018, 69, 93-112. [CrossRef]

17. National Wildfire Coordinating Group. Wildfire Suppression Tactics Reference Guide; PMS 465; National Wildfire Coordinating Group: Boise, ID, USA, 1996.

18. National Multi-Agency Coordination Group. National Preparedness Levels. Available online: https://www.nifc.gov/fireInfo/ fireinfo_prepLevels.html\#: \{\}:text=The $\% 20$ National $\% 20$ Multi $\% 2$ DAgency $\% 20$ Coordination,fire $\% 20$ activity $\% 2 C \% 20$ and $\% 20$ resource\%20availability (accessed on 6 November 2020).

19. Lockheed Martin Enterprise Solutions \& Services. Resource Ordering and Status System (ROSS). 2012. Available online: https: / / famit.nwcg.gov/applications/ROSS (accessed on 6 November 2020).

20. Belval, E.J.; Calkin, D.E.; Wei, Y.; Stonesifer, C.S.; Thompson, M.P.; Masarie, A. Examining dispatching practices for Interagency Hotshot Crews to reduce seasonal travel distance and manage fatigue. Int. J. Wildland Fire 2018, 27, 569-580. [CrossRef]

21. Wei, Y.; Belval, E.J.; Thompson, M.P.; Calkin, D.E.; Stonesifer, C.S. A simulation and optimisation procedure to model daily suppression resource transfers during a fire season in Colorado. Int. J. Wildland Fire 2017, 26, 630-641. [CrossRef]

22. California Governor's Office of Emergency Services. California State Mutual aid Pre-Incident Preparedness Guideline. Available online: https://www.caloes.ca.gov /FireRescueSite/Documents/California_State_Mutual_Aid_Pre-Incident_Mobilization_ Preparedness_Guideline.PDF (accessed on 6 November 2020).

23. Simpson, H.; Bradstock, R.; Price, O.A. Temporal Framework of Large Wildfire Suppression in Practice, a Qualitative Descriptive Study. Forests 2019, 10, 884. [CrossRef]

24. Holmes, T.P.; Calkin, D.E. Econometric analysis of fire suppression production functions for large wildland fires. Int. J. Wildland Fire 2012, 22, 246-255. [CrossRef]

25. Calkin, D.E.; Stonesifer, C.S.; Thompson, M.P.; McHugh, C.W. Large airtanker use and outcomes in suppressing wildland fires in the United States. Int. J. Wildland Fire 2014, 23, 259-271. [CrossRef]

26. United State Department of Agriculture. Aerial Firefighting Use and Effectiveness (AFUE) Report. Available online: https: //www.fs.usda.gov/sites/default/files/2020-08/08242020_afue_final_report.pdf (accessed on 6 November 2020).

27. Oregon Department of Forestry. Aviation Procedures Manual. 2008. Available online: https://www.fs.fed.us/r6/fire/pnwcg/ aviation/2008/08MasterAPM-Edition.pdf (accessed on 6 November 2020). 
28. Jolliffe, I.T.; Cadima, J. Principal component analysis: A review and recent developments. Philos. Trans. A Math. Phys. Eng. Sci. 2016, 374, 20150202. [CrossRef] [PubMed]

29. Agrawal, R.; Imielinski, T.; Swami, A. Mining Association Rules between Sets of Items in Large Databases. In Proceedings of the 1993 ACM SIGMOD International Conference on Management of Data, Washington, DC, USA, 26-28 May 1993; ACM Press: New York, NY, USA, 1993; pp. 207-216. [CrossRef]

30. Cha, D.H.; Wang, X.; Kim, J.W. Assessing Lightning and Wildfire Hazard by Land Properties and Cloud to Ground Lightning Data with Association Rule Mining in Alberta, Canada. Sensors 2017, 17, 2413. [CrossRef]

31. Yu, L.; Bian, F.L. An Incremental Data Mining Method for Spatial Association Rule in GIS Based Fireproof System. In Proceedings of the International Conference on Wireless Communications, Networking and Mobile Computing, Honolulu, HI, USA, 12-16 August 2007; pp. 5983-5986.

32. Jafarzadeh, A.A.; Mahdavi, A.; Jafarzadeh, H. Evaluation of forest fire risk using the Apriori algorithm and fuzzy c-means clustering. J. For. Sci. 2017, 63, 370-380.

33. Waskom, M.; Gelbart, M.; Botvinnik, O.; Ostblom, J.; Hobson, P.; Lukauskas, S.; Gemperline, D.C.; Augspurger, T.; Halchenko, Y.; Warmenhoven, J.; et al. Mwaskom/Seaborn; European Organization for Nuclear Research: Genève, Switzerland, 2020. [CrossRef]

34. Hunter, J.D. Matplotlib: A 2D Graphics Environment. Comput. Sci. Eng. 2007, 9, 90-95. [CrossRef]

35. Belval, E.J.; Wei, Y.; Calkin, D.E.; Stonesifer, C.S.; Thompson, M.P.; Tipton, J. Studying interregional wildland engine assignments for large fire suppression. Int. J. Wildland Fire 2017, 26, 642-653. [CrossRef]

36. Gebert, K.M.; Black, A.E. Effect of Suppression Strategies on Federal Wildland Fire Expenditures. J. For. 2012, 3, 65-73. [CrossRef]

37. Butry, D.T.; Gumpertz, M.; Genton, M.G. The production of large and small wildfires. In The Economics Forest Disturbances; Springer: Dordrecht, The Netherlands, 2008; pp. 79-106. 